Check for updates

The BMJ

Cite this as: BMJ 2021;372:n60

http://dx.doi.org/10.1136/bmj.n60

Published: 8 January 2021

\section{Covid-19: Health and social care staff must be vaccinated now, says BMA}

\section{Zosia Kmietowicz}

The BMA has made an urgent call for all health and social care workers to be vaccinated by the end of January and for those at greatest risk of contracting covid-19 to be vaccinated within two weeks. It said that this was essential, to protect an already depleted workforce and to help prevent the NHS becoming overwhelmed in the next three weeks.

The government's approach to vaccinating staff has been ad hoc and often chaotic, said the BMA. While some hospital trusts and general practices had been able to vaccinate reasonable numbers of staff, others had vaccinated only very few or none at all.

The slow rollout of vaccination is leading to serious staff absences because of either covid-19 infection or the need to quarantine or isolate, which is affecting patient care, said the BMA. It also backed calls for second doses of the Pfizer-BioNTech vaccine to be offered as soon as possible, in line with World Health Organization guidance.

The BMA's chair of council, Chaand Nagpaul, said, "There are almost 27000 patients with covid-19 being treated in hospitals in England-an increase of more than $50 \%$ since Christmas Day. Hospitals are becoming like war zones, and healthcare workers are the exhausted foot soldiers on the front line. GPs are similarly pushed to the limit, delivering an unprecedented mass vaccination programme in the community seven days a week.

"All of these workers are at constant risk of becoming infected, yet they are, beyond all doubt, the most important cog in the covid-19 'care machine.' If they fall ill with the virus and cannot work there will be reduced care, fewer vaccinations given, fewer medical procedures, and fewer patients getting better and going home from hospital, where they may then need GP care. They are also at huge risk and working often 18 hour days."

He called for assurances that the government could supply the 13 million vaccinations promised by mid-February and that health and care staff could book appointments to be vaccinated from next week.

On 7 January NHS England sent a letter ${ }^{1}$ to trust chief executives, primary care networks, general practices, and people officers saying that they needed to vaccinate health and care workers, in line with the Joint Committee of Vaccination and Immunisation's prioritisation.

The letter said that, by mid-January, trusts would be established as "hospital hubs" responsible for vaccine delivery, with priority going to frontline staff who are "at high risk of acquiring infection, at high individual risk of developing serious disease, or at risk of transmitting infection to multiple vulnerable persons or other staff in a healthcare environment.”

\section{What healthcare staff told us}

The $B M$ / made a request on Twitter for healthcare workers' experiences of accessing vaccinations. Here is a selection of responses.

\section{Like clockwork}

Consultant anaesthetist: "We are lucky enough to have business the last nine months, but the hotel and events staff were put to organising vaccinations in our hospital. It ran like CLOCKWORK. Multiple channels of people being vaccinated en masse, with appropriate social distancing in place.

"That' $d$ be my advice-use these skilled people in the events industries that work in venues that are currently closed. Let them feel involved in all of this rather than feeling redundant. They have amazing skills at logistics and large scale event organisations. Our hotel and conference team were absolutely fantastic. I was overcome with gratitude and amazement at how efficient the whole thing was organised and deployed."

General surgery specialist trainee, London: "I received my first dose vaccine on 30 December. We were sent an email by the trust to register our interest to have the vaccine prior to Christmas. We also had to do risk assessment (which would indicate whether we were high say that I could book my vaccine slot: I received my first dose on 30 December."

Respiratory physiologist, Swansea: "We were given dose 1 of the Pfizer vaccine on 16 December-as soon as available in our hospital. Second dose has been delayed until 11 weeks post-\#1 potentially. Happy to have had the opportunity for one dose of a vaccine even if the second dose proves to take longer than planned." Renal consultant: "It was a huge relief to be offered a vaccine in the last week. My husband, also an NHS consultant, with a significantly worse covid risk profile than me, was also able to take up the opportunity for vaccination this week.

"We have been fighting in the front line of covid soaked wards and healthcare environments, but we have not been afforded appropriate PPE [personal protective equipment] for our own health and safety. Healthcare leaders have not stood up for us on this front. Vaccination at least offers a real protection for us-far greater than the paper masks and the plastic aprons that are just not adequate."

General practice trainee, Cambridgeshire: "I'm working on a covid ward and managed to get my covid vaccine last Saturday. Received my vaccine from Peterborough Hospital as we are in the same trust and [after] some excellent work by our acute medical consultant who was working hard to contact us when slots were made available. Staff were incredibly efficient about giving the vaccine, and there was useful information on the consent forms and information leaflets."

\section{Leftovers} a conference hotel attached to our hospital. It's had no risk or low risk). I then got an email on 24 December to 
Locum consultant in anaesthetics and critical care, Yorkshire: "One of my colleagues posted on the consultants' WhatsApp group that a nearby general practice had some spare doses from a session vaccinating vulnerable elderly patients and were keen to offer them to healthcare workers rather than see them wasted. As I had heard nothing from our management about a planned start date for staff vaccination, I contacted the health centre and got an appointment for the next day-Christmas Eve! I decided to make the eight hour round trip to get vaccinated, and I'm glad I did."

\section{No word yet}

Respiratory specialist nurse working on a covid ward: "Unfortunately, along with all of my colleagues we have heard absolutely nothing about getting the vaccine."

Frontline hospital doctors, Liverpool: “To date, we haven't heard when we will get the vaccine if at all. There is a hospital we're affiliated to where we could get it; however, we received angry emails telling us not to go there for the vaccination until told."

\section{Frustrations}

Gastroenterologist, doing aerosol generating procedures: "Very difficult to understand when I was to get one. Trust is obscure and difficult, so I went elsewhere and was vaccinated on 24 December via a mass vaccination centre 50 miles away in tier 2 , when I was from tier 3 . Nothing yet on whether my second dose has moved. Disgusted and felt ashamed and guilty for having to source [it] myself. NHS does not care for its doctors ...34 years of an abusive relationship."

GP: "I was told by my practice that I was not yet eligible for a vaccine and to wait my turn. I know of some GPs who have had the vaccine. I do not understand the inequality."

Minority ethnic GP working in North Yorkshire: "Until 4 January no offer of a vaccine. Got a general mail to all staff today asking who would like to have one when there is surplus!"

Oncology services, Wales: "I received the Pfizer vaccine during the second week of rollout. I am extremely angry that the science about Pfizer vaccine is being ignored and the interval between my booster increased with no trial evidence to support it. I question the decision and the efficacy of the vaccine I consented for."

Radiologist, Scotland: "We were sent an email around 7 December saying vaccination was about to start and inviting us to make (two)

appointments. I received my first dose 10 December and have an appointment for 11 January for my second dose. Many of my colleagues have managed to get their first dose too.

"Sadly, our trust has had to cancel our appointments for the second dose in accordance with the government's instructions. This is disappointing on many fronts, not least in view of Pfizer's statement and issues around consent."

Doctor, NHS Lothian: "Phone number to arrange; absolute chaos to start; tried more than 50 times; always diverted to useless message. Eventually got through; initial appointment changed; given two appointments. During call I had to 'guarantee' that I would be free for 'essential second dose.' First dose 14 December, no problem. I'm now told in generic email that second appointment will be cancelled! Unable to contact anyone to discuss/complain.

"In all my time in medicine I have NEVER been more annoyed-feeling deflated and cheated. The loss of good will at this crucial time in the history of NHS may have huge repercussions in an already fatigued workforce."

Nurse consultant, NHS hospital trust: "I received my second dose on 30 December at the 21 day point. Then on 31 December the changes to the schedule were announced as applying to Pfizer, as well as the newly approved Oxford-AstraZeneca vaccine. I have a range of feelings about this: guilt, as I have had two doses to the manufacturer's schedule; concern that patients were consented to have a second dose at 21 days and were excluded from first dose if they could not accept the second in target time frame; lots of difficult conversations and extra work ahead as we cancel and rebook people. I will be continuing to help vaccinate staff through January."

Forgotten community
Community nurse, Bath: "I have absolutely no idea when we will get vaccinated or who will be vaccinating our housebound patients who are vulnerable as have carers-will they be vaccinated? I feel that community teams get forgotten."

Occupational therapist, working frontline domiciliary care team: "I do daily visits to people's homes. There's talk of the vaccine coming soon but nothing concrete. Only information is that I could be asked to run to a 'last minute available vaccine space,' so keep my mobile at hand. In a nutshell, not enough to go around-yet."

Daughter of carer, Somerset: "My mum is 63 , considered overweight, and [minority ethnic]. She does on average 70 hours a week, visiting over 50 different clients in their own home. She is not paid much more than minimum wage and is given basic gloves, mask, and pinafore.

"Some of the clients in the area have tested positive for covid-19. She is given weekly tests for covid. She has emailed her office to ask if she will be getting a vaccine and if her colleagues who work for the same company in care homes have received the vaccine. They have not replied."

NHS England and NHS Improvement. Letter: Operational guidance-vaccination of frontline health \& social care workers. 7 Jan 2021. https://www.england.nhs.uk/coronavirus/wp-content/uploads/sites/52/2021/01/C1008-Operational-Guidance-Vaccination-of-Frontline-Health-SocialCare-Workers-7-January-2021.pdf.

This article is made freely available for use in accordance with BMJ's website terms and conditions for the duration of the covid-19 pandemic or until otherwise determined by BMJ. You may use, download and print the article for any lawful, non-commercial purpose (including text and data mining) provided that all copyright notices and trade marks are retained. 